\title{
The WRITER'S STUDIO with Philip J. Deloria
}

Langston Hughes learned the art of storytelling from his grandmother. Joseph Heller got his best ideas riding the bus. Flannery O'Connor surrounded herself with pet pheasants, ducks, and peacocks. Historians, too, have special ways of working that are worth sharing. In May 2021, Thomas G. Andrews and Brooke L. Blower asked the scholar of Indigenous history, art, and culture Philip J. Deloria to answer questions about finding inspiration, organizing thoughts, and the pull of family pasts.

Deloria is a trustee of the Smithsonian Institution's National Museum of the American Indian, an elected member of the American Academy of Arts and Sciences, and the Leverett Saltonstall Professor of History at Harvard University. He is the recipient of numerous prizes and the author of many publications, including Playing Indian (1998) and Indians in Unexpected Places (2004), as well as the preface to The World We Used to Live In: Remembering the Powers of the Medicine Men (2006), the final book written by his father, the Sioux scholar and activist Vine Deloria, Jr. Philip Deloria's most recent book is Becoming Mary Sully: Toward an American Indian Abstract (University of Washington Press, 2019).

Tell us about how you usually write. Do you have any special techniques for getting words onto the page?

When it's everyday writing - small things, academic reports, talks-I try to write whenever and wherever possible. You have to do so in order to get that kind of work done. But when I'm looking at long- form writing, or something special, I kick into gear with a number of rituals and techniques.

I like to be at my computer at 8:00, breakfasted and with no distractions. I will dress nicely. Not often, but sometimes, I will go so far as to wear a coat and tie, just to remind myself of the seriousness of what I'm doing. There's a bit of an antiquarian groove to it as well.

If I'm struggling a bit, I may read a couple of pages of someone else's good clean prose, just to get that voice in my head. I'll try to work for two and half hours, and then take a half hour break. I'll work for another hour and a half and then stop. In the afternoon, I'll return, but only for a round of editing. If I'm following this routine as part of a self-imposed writer's retreat (usually in the winter, in northern Michigan), I'll go ski for a couple of hours, come back, and have a glass of wine and some cheese. Quite delightful! If I'm just working at home, I'll use the afternoon to catch up on email and other tasks. In the evening, I'll read what I've written that day, so that I'm thinking about it while sleeping, and ready to pick up the thread the following morning.

Some writers are amazing on the page-eloquent words, artful sentences. I know that I'm not that kind of writer. My strength, as I see it, lies with ideas - and not just the big idea that powers a book, but also with the intermediate ideas that create chapters and sections as well as the intimate ideas that shape paragraphs and sentences. So I work hard to cultivate ideation.

The unconscious sends us gifts, I believe, and we can prime it to do so. Think hard on a problem and then put it away completely. Then, strive to place yourself in a state of "attentive distraction."

(C) The Author(s), 2021. Published by Cambridge University Press 
I tend to wake up early, for instance, and lie in a kind of reverie for maybe an hour, just letting thoughts come and go. I take very long showers. Like so many others, I go for walks or runs, though I find that running is the hardest way to capture ideas.

Sometimes I write ideas down, but not always. Sometimes I remember them. Sometimes I forget them. Even that is okay. They may be back.

I knew that I had become a professional the day I realized that I could almost always count on myself - both through my conscious cognition and my unconscious ideation-to have something to say. I became confident that, with a few days and a couple of showers, something interesting would be revealed to me. And while one might imagine being terrified at the prospect of losing that ability, I've never thought of it as any kind of personal gift or talent. It's just the universe smiling at me, and I understand that a day will come when it will smile on someone else. And that will be fine.

\section{Did you grow up with lots of books? When did you start writing?}

My grandmother was the children's librarian at the Davenport Public Library, in Iowa. My mom was a librarian as well. And of course, my father was a writer, with a huge library that grew with every passing year. So I can recall being peppered with children's books early on. In middle school, my brother and I would make our way after classes to the Fairhaven Library, in Bellingham, Washington. We'd pick out a book and read until my mom finished her shift at 9:00 pm. As I grew older, I started reading out of my father's library-nothing academic or literary, though; mostly the classic mystery writers: Raymond Chandler, Dashiell Hammett, Ross McDonald.

That part of my life was devoted to music, not writing. I learned the same rudiments as everyone else, and was incurious about anything more. Later, I earned an M.A. in journalism and, in a news reporting class, I realized that I was an average writer at best, with a poor command of grammar and a tendency toward wordiness. In graduate school, friends like Catherine Corman and Jenny Price helped me pull myself together around technique, and I first came to understand that there was a modest and challenging joy to be found in it.

\section{Which writers do you most admire and why?}

My hands-down favorite writer is my friend Carlo Rotella, and that's in large part because much of what I've learned about writing over the last couple of decades has come in the form of gifts from him. Carlo is an apostle of craft, skill, mastery, and work. He writes great prose, to be sure, but he has also taught me about blocking, outlining, editing, structure-all those things I pretended to do, but never actually did. Talking to Carlo, I am always reminded that craft itself produces ideas and insights, unbidden thoughts that transcend the nuts and bolts work. That's why we tell our students that writing is thinking, and that thinking may well be incomplete without writing.

\section{Which scholars do you most admire as writers and why?}

I like scholars with a gift for narrative, a touch of wit, and a deft touch with analysis. Over the years I learned a lot from Patty Limerick, Bill Cronon, and Richard White, and I admire their writing greatly. Patty has such a fabulously whimsical presence, and I appreciate the way she translates it into prose. Bill is so interested in storytelling, and I love the ways he writes narrative across a range of scales, and does so with forethought and intent. Richard is a historian's 
historian and some large part of that stems from his narrative gifts and his ability to process vast amounts of information into legible pieces. If you add Donald Worster into that mix, with his passion-and-preaching sensibility, you have the New Western History "Gang of Four" and an explanation for their success that is more literary than historiographic.

I should add, though, that there are many others: I enjoy the clever intelligence of my colleague Jill Lepore, the passion of my pal Walter Johnson, and the control and poetic sensibility of my friend Tiya Miles. I am fascinated by the pull of Saidya Hartman's writing. I've always loved reading smart anthropologists like Anna Tsing, James Clifford, and Michael Taussig. And I could go on and on!

Images play an important role in your work as inspiration, evidence, and more. What tips do you have for scholars wishing to do more with non-textual sources?

Unless one works systematically-like an art historian-to make an image into a text, it will slip back into being a mere illustration. It requires a suite of skills distinct from the reading of written evidence. I've always seen those skills-defamiliarization, close interpretation, deductive reasoning, creative speculation-as defining an American Studies analysis, and it has been at the methodological center of everything I do. I trace these methodological origins to Jules Prown's systematic practice for reading material culture. Prown, perhaps more than anyone else, taught me how to think - and that structure for thinking was completely tied up in the methods of art history, material culture, and landscape studies.

\section{You have mastered the genre of essay writing. What is it about essays, vignettes, and other short forms of writing that you find so compelling?}

Thank you for the compliment! First, it does indeed seem to me that it can be unusually satisfying to operate at the register of the essay, in which people, stories, and cases have an immediacy and importance relative to the analytical bits. There's a visible wholeness to it that I love. Second, the really good long-form question or idea, one that demands a book, is rarer than we might otherwise imagine. I've had maybe five or six of those big ideas, the ones that excite you to write 300 pages. But I've had a lot of ideas that ask for thirty pages and no more. I've always cautioned my students that there are a variety of different logics that can be used to connect story and analysis and that it's important to match the logic to the form. In my first two books, for instance, the fifth chapters originated in the logic of the conference paper: story, analysis, and significance crammed into twelve pages. That's not the logic of a chapter, and I really struggled to retrofit them. They remain the weakest chapters in both books. The logic of the essay, for me, is in the Goldilocks zone: not too long or too short, but just right.

Your own family history has assumed an increasingly important role in your academic writing, most strongly in your latest book, Becoming Mary Sully. Was that something you expected to pursue?

Absolutely not. I was a middle school band and orchestra teacher. Then played a bit of music and worked in video production. You might read that personal path as an effort to evade my family history, and you'd be right.

The family keeps coming back, though, because it is an extraordinary one, full of interesting characters. They confront achingly painful situations that, to a frightening degree, translate directly into insights that speak to the big questions. My father understood the family in metaphysical terms. 
I rejected that interpretation for many years, but I may be coming around to it. Mary Sully's art, for instance, was a magical experience for me-and I'm not using "magic" as a genial, empty adjective. I kept the art with me for a long time-too long (it's now in secure, climate-controlled storage). I worked with reference photographs while I was writing, but I often pulled the pieces out of their boxes and spent time with them, feeling the life that continues to attach to the paper. The touch, and especially the scent of them: it's incredibly powerful.

There are emotional connections that span generations, barely perceptible and perhaps even imaginary. I'm enough of a historian to be skeptical of those feelings, but enough of a mystic to take the experience seriously. And that experience points directly to the sense-frequently articulated by my dad-that there has been a mission in the family for well over a century, and that we are all obliged to figure out our own distinctive task.

In Becoming Mary Sully, you offer something of a mission statement: "I tell histories that try to close the gap between the analytic and the affective, between meaning and feeling. I will oscillate between narrative and formal analysis, between historiography and biography, between critical interpretation and context." What do you see as the crucial writerly moves that enable you to render such oscillations in ways that grab, orient, and compel your readers? Mary Sully's artwork has a politics and a message, contained within the formal aspects of the art-the development of iconography across three images, defined as a triptych. The first task, then, was to read the images as well as I could, and to render those readings into short, imagebased narratives that did the simultaneous work of description, interpretation, and analysis.

Alas, formal analysis is not considered the cutting edge of the art historical world, so the second task, as I came to understand it, was to demonstrate why this particular art demanded such analysis. That, in turn, meant linking the readings to a thick description of context: biography, psychology, modernist art, Native arts, Dakota aesthetics, family history, and the politics of American settler colonialism. At the same time, art-and this art, in particular, for me-has an affective dimension. A writer has to try to convey some sense of that feeling, and it's not enough to simply describe one's own affect. You have to create conditions under which readers can enjoy their own affective experience.

That is the third task, the most important one, and the one that I wished I might have done better. But I am basically with Walter Benjamin on this question. One assembles a constellation of things-images, contexts, evocations-and then hopes for the unpredictable lightning to strike. It's a species of argument in which one develops concise analyses-cause and effect, change over time, contingency and continuity-while simultaneously creating conditions for non-analytical, affective experience. It will not surprise you to learn that it was essential to me that the reproductions and design of the book advance that goal.

In your recent response to David Silverman's critique of Native American and Indigenous Studies in the American Historical Review, you note that "historical narratives have tangible, material consequences." How, if at all, does your awareness of these consequences affect your writing process?

Indigenous peoples the world over are constantly subject not only to material dispossession, but to rhetorical violence: erasure, belittlement, appropriation, marginalization, benevolent tokenism. It's a long list. I believe that words matter, that they shape beliefs, which then shape actions. I was not asking Silverman, or any historian, to pull their punches. Rather, I was asking historians to stop pretending that their words are only academic. 
Don't we want our research and writing to change the world in some way? We do! We have to admit, then, that our work may have unintended consequences; that it may actually change the world in ways that do harm. Carrying that awareness into the writing process gives writers a brand new way to contemplate the power of words. The kind of intense calculating that we bring to our writing-swap this word for that one; eliminate that adjective; trade those two clauses-cannot simply be literary, technical, or analytical; it has to have an anticipatory political vision as well.

You have previously discussed the centrality of narrative momentum to your historical writing. First, can you explain how you think about narrative momentum? And second, can you pull back the curtain on your process for developing-or excavating-this? How, for example, did you incorporate narrative momentum in Becoming Mary Sully, a story that begins and ends with the same triptych and centers on the work of an artist whose oeuvre is largely undated?

For me, a narrative moves best when it combines stories and analyses at all possible registers-a utopian goal. Chronology is the easiest, so one starts by charting out the meta-story: where does it begin and end, and what falls in the middle? That meta-story is complicated by all the smaller stories one also wants to tell. Putting those small stories in a kind of sequence (not necessarily chronological!) means that you let go of the big story for the moment and start figuring out the plotline. You focus on character development, scene setting, and the establishment of moments of reveal and surprise-which means that you scramble up the chronology of the meta-story. The tension between the scramble and the big story makes up the dramatic narrative.

The analytical aspect is equally important. Small stories don't exist because they are inherently interesting, but because they have to make a point. At the paragraph or section level, then, you establish a rhythm of beats and stepbacks: tell a good story, introduce some evidence, and then take a step back, assume an interpretive voice, and tell us what it all means. Rinse and repeat. The writer's Holy Grail is the story that is so evocative and rich it tells its own analysis and no stepback is needed.

At this point, it's all pretty complicated, because you are trying to juggle a big story and a big analysis, a series of small stories and small analyses-and those small analyses have to build sequentially. The heart of it all, it turns out, is not the dramatic unfolding, but the analytical motion of the narrative.

Here, frankly, is where I venture into "do as I say, not as I do" territory, because I find it hard to sustain such an intense level of focus, intentionality, and planning. As that failure unfolds, as it always does, I turn back to structure, and in particular to chapter- and section-level arguments. These reorient my head in a different way: not to the big narrative, or to the local stories and analyses, but to the organizing principles that will take me from the opening question to the concluding answer.

So in Mary Sully, the question that frames the first image is this: Is it possible to understandand thus to value-this utterly bizarre piece of art? And the answer-unsurprisingly-is "yes, and here is how." I'd like to think that the book has narrative movement at multiple levels: the local story and the interpretive work, the nested contexts, the big argument. The metaphor that I use as a signpost, to remind readers of the task at hand, is of peeling the onion. It has the great virtue of being absolutely true-the more you know about this art, the more the art speaks with a rich, meaningful voice. 
You managed to write your third book while holding a succession of time-consuming and energy-sucking administrative positions. What advice do you have for other historical writers who are facing similar or analogous constraints?

I developed a very conscious strategy for crafting the project along multiple lines. One was my own interpretive experience of the art, which was slow and personal. Another was as a research project that could involve students. An extraordinary student named Jordan Weinberg did remarkable work unearthing the fine-grained details of the biographies of the people Mary Sully chose to represent.

Most important, since I was unable to devote significant time to the project, I developed it in the form of a lecture. I would talk through the story with an audience, respond to questions, and collect thoughts. A young man in Nebraska observed that he had synesthesia and that his perceptual experience of the world looked something like Sully's art. Friends in Taiwan made me question my assumptions about the sequences and patterns through which one might read the images. Many people had things to say about the "threeness" of the triptychs. And of course, I benefitted from observers knowledgeable about Plains Indian women's arts and about American modernism. I'd take in these observations, and then go home and think about it for a while. Three months later, I'd do another talk with a set of new ideas.

I kept iterating that way for years, while also living my administrative life. In a very real way, the book is a collective, collaborative project, developed with thousands of other people. At the end of it all, I had the best talk of my life-but I had also broken my own rule about matching logics and forms. It took a leave year and two drafts, completely reverse-outlined, to arrive at the final structure of the book.

\section{What does it take for a sentence to satisfy you?}

I mentioned earlier that I don't regard myself as a literary writer. Indeed, I'm completely stressed out and self-conscious about my responses to your questions! In my own sentences, I've given up on looking for clever word play or aesthetic beauty. I'm just happy if a sentence conveys an idea in a coherent way.

I have my checklist: Active voice verb? Cut extra adjectives? Eliminate that " $\mathrm{x}$ and $\mathrm{y}$ and a and b" rhythm that always seems to plague me? Get rid of a few dashed interjections, which I also overdo. And so on.

My ambitions, in other words, are modest. Mostly, I just want to get out of my weird, vague, creative "thinking" voice, and into a voice that focuses on clarity and communication.

\section{Do you outline?}

I do a preliminary rough outline. I have to know where I'm headed and what sequences will get me there. For the analytical framework, I often do a bushy tree diagram: one first-order question that will power the piece; four or five second-order questions that correspond to chapters or sections; several third-order questions that will structure sections or sub-sections.

While such a diagram is quite helpful, the act of writing generates new insights that outlines cannot anticipate. If you over-outline and execute your plan too faithfully, you cut yourself off from the generative act of writing itself and so become mechanical. 
After writing, then, I reverse outline and rethink. For Mary Sully, I wrote every topic sentence of every paragraph of my first draft on large sheets of paper, stuck them around our bedroom and then walked through the structure of the book, or lay on the floor looking at it all. A major restructuring followed.

\section{What do you do when you get stuck?}

Put it away for a while.

But before I do, I try to identify the problem that is holding me back. Is it analytical or argumentative? Expressive? Emotional? Evidentiary? In most cases, I'm betting that a way forward will appear. If it doesn't, I may return to the scene of the crime and just try to power through. Or put down a placeholder and see if the situation doesn't change for the better. I don't invest much time or energy agonizing about it.

Stuckness, for me, is not an existential condition. Like so much else in life, it's just a problem to be solved.

\section{What role do your research methods and techniques for organizing data play in your writing process?}

I'm envious of friends with amazing data management systems or of scholars who work with large collections of data. I'm quite primitive in comparison!

These days, one can move relatively quickly through an archive, shooting images of documents and using a program to organize them. I am slow in archives, in part because I often pause the reading and recording to write a page or two. Sometimes you look at a document and you have a flash of insight. I've found that, while I'll remember the idea later on, there's an excitement and immediacy that makes it important to capture in the moment. If you find a source that makes you gasp, how can you just file it away and go on to the next document in the folder? Writing in the archival moment is a way of honoring the pastness in which you're trying to immerse yourself. You have to remember that you're touching things that were touched by someone else back in the day. Those things have certain powers and you must approach them with respect.

I see myself as an interpretive scholar-it makes sense to me to begin by close reading individual texts, stories, people, objects. So my writing often starts with only a few key items. The organization of other texts follows, as I try to surround those texts with additional evidence that reveals genres of meaning and modes of production, distribution, consumption. These things can be further contextualized and eventually theorized.

In other words, I don't organize data and let it structure the writing; I begin with interpretive writing and let it organize the data.

\section{Do you share your drafts with anyone? What is your revision process?}

I try to make myself pleased with a draft, and then I share it with a small circle of friends. While I write on a computer, I always do my first round of revision on paper. That round focuses on structure and so I need to see more than a computer screen can offer. I like to give this round of structural revision a physical character. Often, I'll go into a library or reading room-any place with big tables-and lay out an entire chapter so that I can literally walk through it with a 
pencil. I move sections, rewrite transitions, add clarifying material, cut bits as ruthlessly as I'm able. I enter those changes and then turn to a second round of revision, onscreen, which focuses on the coherence of the paragraph-as a tightly-articulated idea complex-and the sentence-as the clear expression of a thought. Of course, these are ideals, not rules, so there is variation from project to project. Sometimes I write something up, take a quick second pass, and hit "send."

\section{What do you try to teach your students-especially your graduate students-about writing?}

Writing is thinking; thinking is writing.

Writing is a learned and practiced craft, not a work of magic or mystery. Indeed, the magic happens when you are practicing the craft. Literary talent may be distributed unevenly, but no one is "born" a writer.

Find ways to pose problems for your unconscious mind to solve, as well as strategies for bringing those solutions to the surface. If you can find a metaphysical quality in this intentional practice, by all means do so.

De-cathect! Your writing is not you; you are not your writing. Treat your own text like a distanced object, and you'll be a better writer and a happier person.

Aim for a 50-page chapter: it's perfectly pitched to a reader's attention span. Less than that and you haven't developed enough evidence and analysis; too much more than that and you don't really have control over the material.

Pay attention! The most interesting ideas can be plucked out of the stream of life, but that will not happen if one is living in a functional, robotic, mechanical way. The odd and itchy little anomaly-usually greeted by a "huh ... that's weird"-is exactly the thread to grasp and pull on. Don't ignore it.

\section{What kind of historical stories do we need more of right now?}

Historians have always used the past to speak to the present. Sure, we might wrestle with "presentism" and philosophize deeply about what past, present, and future owe to one another. At the end of the day, though, we can't help but write out of our present, with an eye toward the future. In that way, historical writing always has the potential to be revelatory and transformational!

Our challenge is to bring that potential to fruition. As far as I can tell, there's no tried-and-true formula for rising to the challenge. So we need historical stories that continue to experiment with format, media, structure, tone, topic. And stories that set out, self-consciously and systematically, to uncover the secret formula.

In Native American and Indigenous history, it's useful to recall that settler colonial theoryprecisely because it is theory-is predictive. It predicts an ongoing project to erase and assimilate the Indigenous, which means that at least some of us need to think of our work as explicitly counter-programmatic. We need to tell historical stories to keep Native pasts, presents, and futures on the table, to defy and decry practices of erasure as loudly and persuasively as we can. At their best, such stories are not only decolonizing-taking on and taking apart the structures 
of forgetting-but also indigenizing - telling new/old stories that center Native people in ways that serve Native cultural and political life and that transform anyone else who takes the time to read and listen.

It's no coincidence that so much Native fiction delves deeply into history. We're all chasing the circle around and around to the point where we meet up with one another. 